\title{
First ever report on the antimicrobial activities of some selected mangrove halophytes of Sundarban against milk spoilage microflora
}

\section{Abhishek Mukherjee*, Subhajit Das, Sabyasachi Chakraborty, Anwesa De and Tarun Kumar De}

Department of Marine Science, Ballygunge Science College. University of Calcutta. India.*Email abmsws@gmail.com.

\begin{abstract}
The study was governed by the objective of investigating the antimicrobial effects of mangrove leaf extracts. The fresh and dried leaf extracts from Avicennia marina (Forssk.) Vierh., Avicennia officinalis L., Aegiceras corniculatum (L.) Blanco, Aegialitis rotundifolia Roxb., Acanthus ilicifolius L, Lumnitzera racemosa Willd., Excoecaria agallocha L. and Sonneratia apetala Buch-Ham. were found to have inhibitory effects on the milk spoilage microflora obtained from curd sample. Methanol and Acetone were used as extraction solvents and in comparison, extracts by acetone were observed to suppress the microbial growth to lesser extents. Leaf extracts of $A$. marina, A. officinalis $\mathrm{L}$. racemosa and $A$. rotundifolia were able to exert relatively greater inhibitory effect on the milk spoilage microbial broth than others, although all the species expressed some degree of suppression. Interestingly $A$. rotundifolia, $S$. apetala, $L$. racemosa and E. agallocha demonstrated greater efficiency in formation of larger growth inhibition zones on the petri plates. The extracts obtained from dry leaves produced greater adverse effects of the microbes than the raw leaf extracts. The data generated were analyzed with the help of 'ANOVA: Single factor' and 'F-test: Two sample for variance' and data sets were of statistical significance at 0.05 level of significance as null hypothesis was rejected.
\end{abstract}

Keywords: Antimicrobial activity; Sundarban; Mangrove; Milk spoilage microflora.

\section{Introduction}

Plants have served as valuable and indispensable sources of natural resources for human beings and apart from their more obvious impacts upon the well being of the ecosystem, they also have proven to be invaluable as repositories of a plethora of biochemical compounds of immense medicinal and therapeutic value and thus have great potentials for producing new drugs effective against debilitating 
ailments. Works by Nascimento et al. (2000), Littleton et al. (2005), Morales et al. (2008) and Panda et al. (2009) are good examples of the prior statement. Even today people who live near to the forests use their ethno botanical knowledge to cure chronic diseases. Tropical and sub-tropical areas of the world are bestowed with abundant floral treasure with untapped potentials to be used as antimicrobial, antiviral and/or antifungal agents. According to the World Health Organization, plants are a source of compounds that have the ability to combat disease, antimicrobial, antiviral and antifungal activities (Gazim et al., 2008). Also they are less toxic to humans and environmentally friendly due to fewer pollutants produced at production lines and have minimal health hazards (Opra and Wokocha, 2008).

The ill-advised and indiscriminate intake of antibiotics have resulted in the global rise in antibiotic resistance among the pathogenic or storage microbes posing some of the more severe problems for healthcare sector and industries (Jacquelyn, 2002; Aliero et al., 2008; Mojab et al., 2008) and thus it has become imperative to discover or invent newer drugs with greater eradicative efficacy against such disease causing microbes. Since plants have always provided us with an array of medicines, it is better to use the help of plants to develop or synthesize new drugs (Nascimento et al., 2000). Apart from this, works such as by Nebedum et al. (2009) have also pointed out to the issues of hypersensitivity, immunosuppression and allergic reactions are widely reported among patients after the consumption of various antibiotic products.

The mangrove flora have been shown to possess novel natural products in their leaves, barks, stems or roots as they thrive in conditions suitable for a myriad of microflora and fauna and mangrove plants have mastered their environments by manipulating the available resources to the best of their usage (Bandaranayake, 2002; Chandrasekaran et al., 2009; Bhimba et al., 2010). Species like Acanthus ilicifolius, Avicennia marina and Excoecaria agallocha have showed significant analgesic activity (Kokpol et al., 1984;
Agoramoorthy et al., 2007). The leaf extracts of Bruguiera cylindrica and bark of Rhizophora mucronata show antiviral activity against Newcastle disease, vaccinia and hepatitis B viruses.

Mangroves are widely used by mangrove dwellers for bush medicine e.g. A. ilicifolius is used for skin disorders, boils and wounds (Bandaranayake, 1999). Numerous medicines derived from mangroves (ashes or bark infusions) can be applied for skin disorders (e.g. Lumnitzera racemosa) and sores, including leprosy. They have been reported to treat different kinds of diseases (headaches, boils, ulcers and diarrhoea). Mangrove plants are a rich source of steroids, triterpenoids, saponins, flavonoids, alkaloids, tannins etc (Bandaranayake, 1995, 2002; Agoramoorthy et al., 2007). Mangrove associate plant Clerodendrum inerme is used for antibacterial activity against some human pathogenic bacteria (Sayyed et al., 2008) and as antifungal against some human and plant pathogenic fungi (Rajkrishnan and Ponnusamy, 2006; Sayyed et al., 2008).

As a preliminary study, it has been found that aqueous and ethanol extracts of some mangrove species have antimicrobial activities (Abeysinghe et al., 2000). Expanding the same research (instead of using aqueous and ethanol extracts), the aim of this study was to evaluate the antibacterial activity of medicinal mangrove plants using other organic solvents viz. methanol and acetone in order to get maximum compound(s) from the different plant materials and screening them in vitro for antibacterial activity against spoilage microbes.

The primary hypothetical objective of the study was to establish and compare the antimicrobial properties of eight true mangrove species viz. Avicennia marina, Avicennia officinalis, Aegialitis rotundifolia, Aegiceras corniculatum, Sonneratia apetala, Excoecaria agallocha, Lumnitzera racemosa and Acanthus ilicifolius against milk-spoilage microbes, through the use of methanol and acetone as organic solvents of their fresh and dry leaf samples. Such studies on the Sundarban 
mangrove fringes in the vicinity of the Hooghly estuary have not been attempted in the past and the results obtained are of immense importance from ecological as well as economical perspective and should serve as reference to any researcher aspiring to works on the subject since this is the very first study on the subject.

\section{Material and methods}

Physiography of the Hooghly
Estuary and Indian Sundarban
The Hooghly Estuary (lying
approximately between $21^{\circ} 31^{\prime} \mathrm{N}-$

$23^{\circ} 20^{\prime} \mathrm{N} ; 8^{\circ} 45^{\prime}-88^{\circ} 45^{\prime} \mathrm{E}$ ) is one of the chief estuaries to comprise the largest deltaic region in the world and is world famous because of its association with the Indian Sundarban. The salient feature of the Hooghly Estuarine ecosystem is the mangrove dominated tidal inlets and canals which is the characteristic component of the Sundarban Ecoregion (Figure 1), although much of it has dwindled during the last decade due to unhindered human encroachment and non-regulated exploitation of the natural resources. The Sunderban has a physiologically dry soil with high amounts of salt.

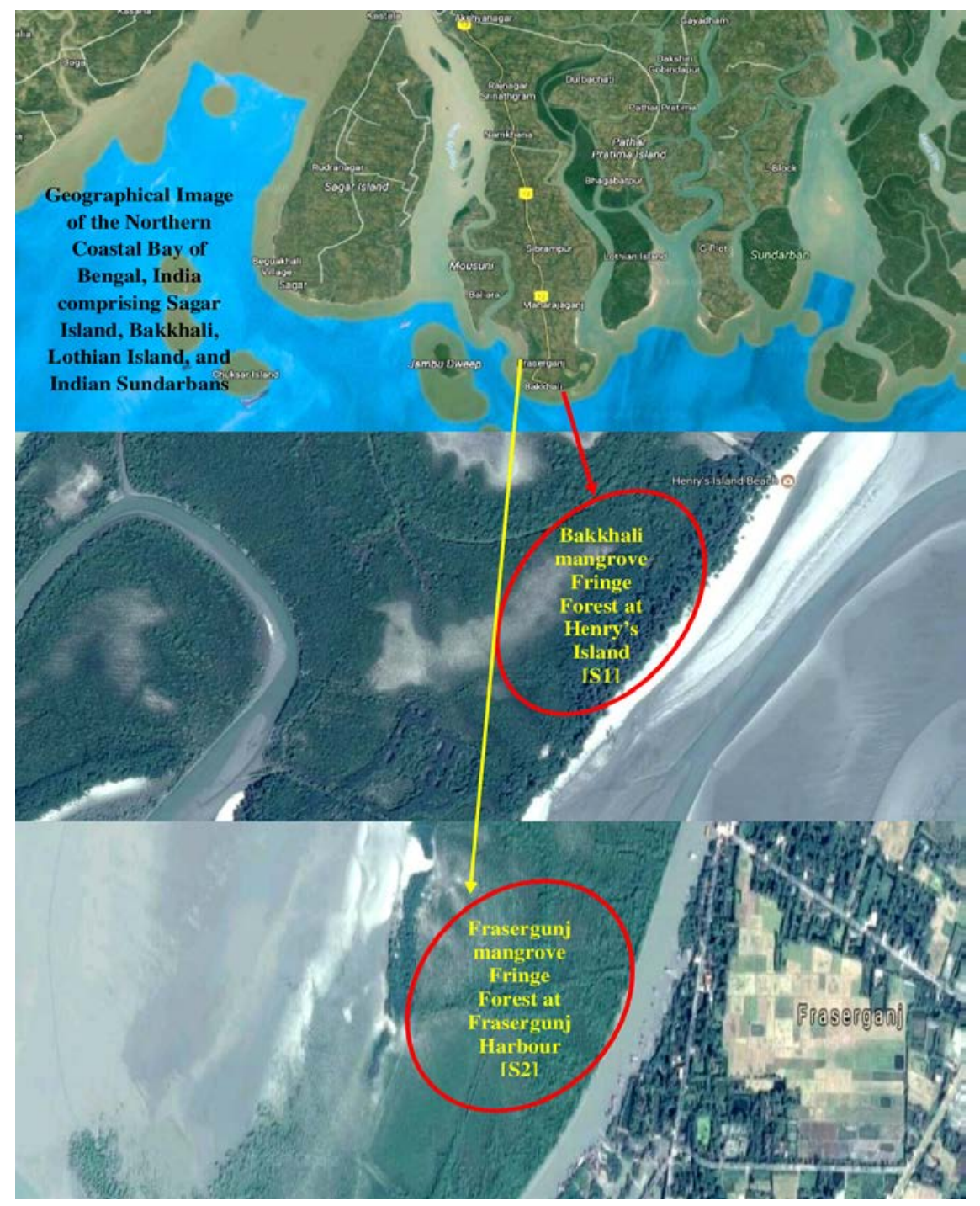

Figure 1. Map of the sampling site. Bakkhali and Frasergunj; the S1 and S2 are demarcating the spot of collection of mangrove plant samples at Bakkhali and Frasergunj beaches, respectively. Image courtesy Google Maps. 
The edaphic characteristics of the region can be silty, sandy or clayey. Sandy sediment layers are generally encountered near the beach tidal flats extending inwards with the aid of sand dunes and tidal creeks. These are coarser and porous and are not suitable for accumulation of organic carbon which ultimately forms the fertile surface layer. That is the characteristic of forest or mudflat sediments with visibly higher diversity of flora and fauna. Although the marine influence brought about by the high tides render the surface layers to be alkaline $(\mathrm{pH}>8.0)$, predominantly it varies from being acidic to neutral ( $\mathrm{pH} 5.0$ to 7.3). The subsurface layers are almost always acidic due to the actions of the anaerobic bacteria and accumulation of litter which ultimately get converted into humic and tannic acids. Another very intriguing feature of the mangrove ecosystem and the beach is the presence of varying degrees of bioturbation which greatly affects the physicochemical nature of this ecosystem, mostly in an ameliorative manner but at times also detrimental (Mukherjee et al., 2016).

The season is generally categorized into three seasons separated by the onset and/or recession of monsoon viz. premonsoon (March-June), monsoon (JulyOctober) and postmonsoon (NovemberFebruary). Semidiurnal tides are observed in this area with meso-macrotidal amplitude, that is, $2.5-7.0 \mathrm{~m}$, with mean current velocities of 117 and $108 \mathrm{~cm} \cdot \mathrm{s}^{-1}$, respectively, during high and low tides (Biswas et al., 2010). A study by Mukhopadhyay et al. (2006) yielded that the discharge rate was higher during monsoon with a mean of $3.0 \pm 1.0 \mathrm{x}$ $10^{3} \mathrm{~m}^{3} \mathrm{~s}^{-1}$ and maximum at $4000 \mathrm{~m}^{3} \mathrm{~s}^{-1}$ during September rains. Considerably lower discharge values were recorded during premonsoon with a mean of $1.0 \pm 0.08 \mathrm{x}$ $10^{3} \mathrm{~m}^{3} \mathrm{~s}^{-1}$ and minimum at $900 \mathrm{~m}^{3} \mathrm{~s}^{-1}$ in the month of May. According to the report, in the lower Gangetic West Bengal, usually heavy precipitation occur during rainy season (June-October) resulting in considerable surface runoff from the catchment areas of Bhagirathi-Hoogly River and its tributaries.

\section{Sampling sites}

The sampling stations were selected based on their physico-chemical parameters mainly focusing on anthropogenically disturbed marine and coastal ecosystems. The selection of stations (Figure 1) was based on the pretext of observing the responses of the biotic communities which are constantly influenced by the ever changing stoichiometry of the ambient media. The following is a short description of the sampling stations:

\section{Frasergunj $\quad\left(21^{\circ} 35^{\prime} 55.33^{\prime \prime} \mathrm{N}\right.$;} $\left.88^{\circ} 14^{\prime} 48.53^{\prime \prime} \mathrm{E}\right)$ : Originally known as Narayantala, Frasergunj is a relatively pristine white beach (greatly disturbed during Hilsa and Winter Migratory fisheries), stretching $7 \mathrm{~km}$ across with high marine influence.

Bakkhali (21 $56^{\prime} 33^{\prime \prime} \mathrm{N}$ and $88^{\circ} 25^{\prime}$ 94” E): Around $3 \mathrm{~km}$ from Frasergunj, this is a sea side resort with long beach bordered by Casuarina trees and presently characterized by the formation of an enormous tidal flat. The area with many sanctuaries, fisheries and resorts is highly perturbed and its flora and fauna are under enormous stress of being constantly overexploited, with very little measures taken by the concerned authorities.

The intertidal beach of both Bakkhali and Fraserganj is thickly populated with red crabs. These species are important agents of bioturbation and cause on the horizontal and vertical stratification of the beach sediments.

The edaphic nature of Fraserganj beach is muddy (more than Bakkhali) and silt with prominent (rhomboidal, lenticular, conchoidal) beach features. On the other hand, absence of mangrove vegetation and the coastal processes along with the anthropogenic stress have rendered the Bakkhali beach to accumulate more sand than silt and mud. Compared to Fraserganj, Bakkhali beach is more bioturbated. The salient feature of the continuous Beach of Fraserganj and Bakkhali is the presence of Casuarina trees and characteristic sand dunes. 
The selected mangrove species

Eight true mangrove species were selected for the study (Figure 2) based on the previous studies on some of the species elsewhere in the world on their antimicrobial potentiality, while some among the selected ones have never been investigated upon before. No studies on these species against milk spoilage have been done so far.

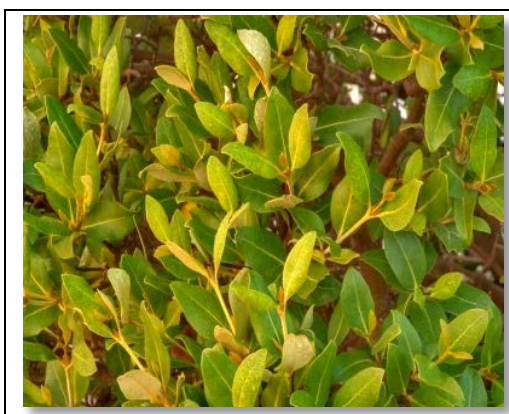

A: Avicennia marina.

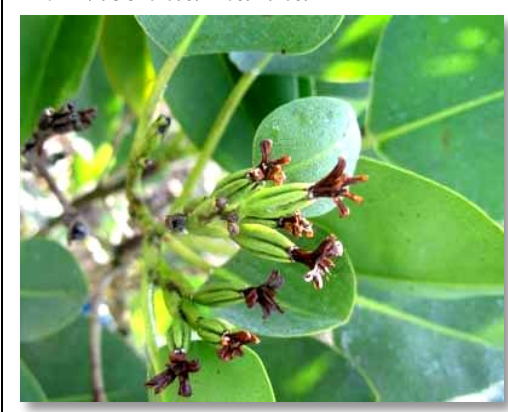

D: Aegialitis rotundifolia.

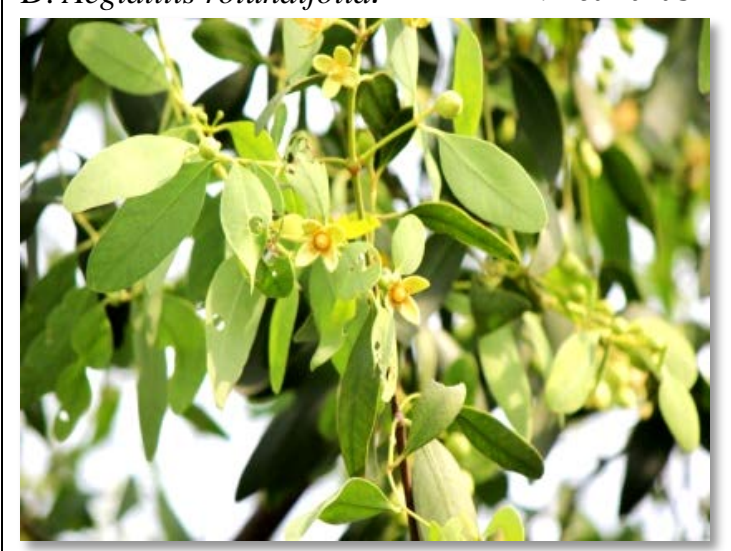

G: Sonneratia apetala.

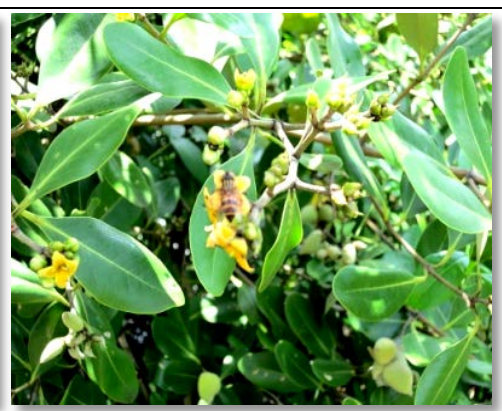

B: Avicennia officinalis.

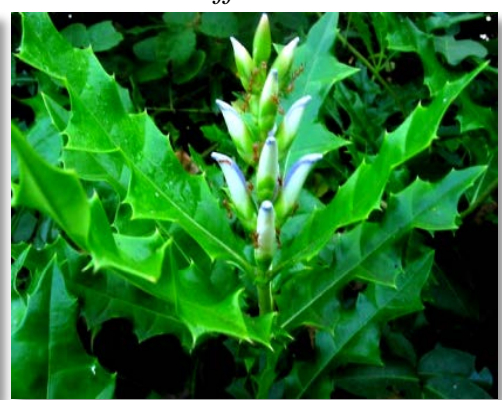

E: Acanthus ilicifolius.

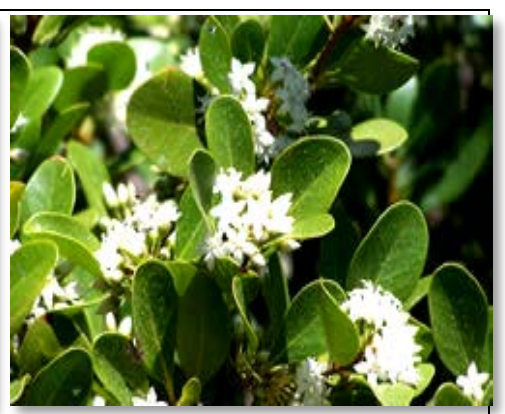

C: Aegiceras corniculatum.

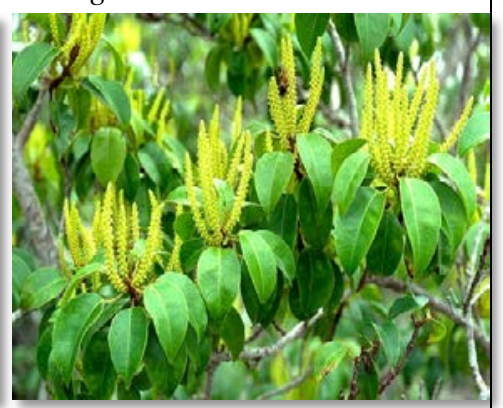

F: Excoecaria agallocha.

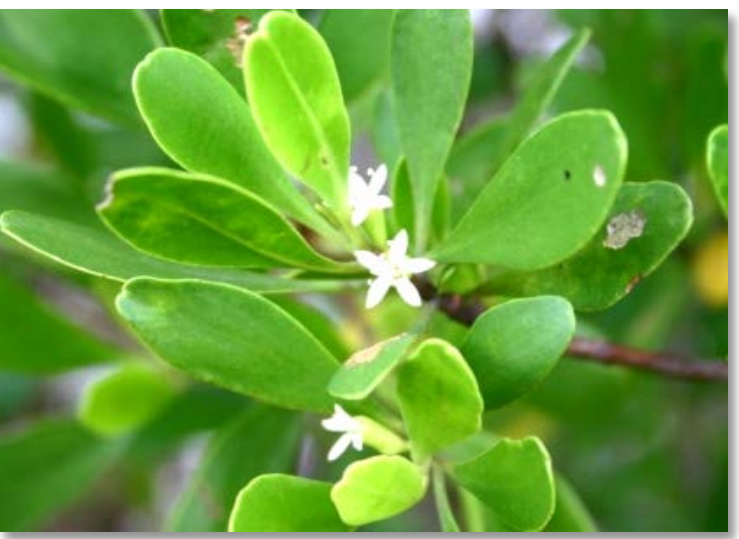

H: Lumnitzera racemosa.

Figure 2. Photographs of the selected mangrove species.

\section{Sample collection and preparation \\ Extraction from raw leaves. The} mature leaves of more or less similar sizes were collected from the eight selected true mangrove species and aseptic conditions were maintained throughout the collection phase. Post collection, the leaves were washed with autoclave sterilized ambient water to wash away any mud or debri and also to minimize osmoticum-mediated damages to the leaves. One gram of fresh 
mangrove leaves of the each species was weighed in separately and taken in two $50 \mathrm{~mL}$ beaker and washed with sterilized ambient seawater water. The leaves were crushed with the help of mortar and pestle separately and the leaf paste was taken in two $50 \mathrm{~mL}$ beakers respectively for each species. $20 \mathrm{~mL}$ methanol was added to one beaker and $20 \mathrm{~mL}$ acetone to the other beaker, respectively. The raw extract of the leaves of respective mangrove species were then left for extraction in room temperature for 7 days for complete extraction. After the extraction, the extracts were filtered with the help of Whatman No. 1 (pore size $11 \mu \mathrm{M}$ ) filter paper to remove the larger debris. The filtrate was next centrifuged at $5000 \mathrm{rpm}$ for $15 \mathrm{~min}$ to remove the fine debris that was not removed by filtration. The clear supernatant was then taken and stored in glass vials and refrigerated at $4{ }^{\circ} \mathrm{C}$ for future study. The extraction procedure is based on the methods by Gulshan et al. (2005) and Saravanan and Radhakrishnan (2016).

Extraction from dry leaves. Freshly collected leaves of the subject species chosen for the study were washed and dried in room temperature for 10-15 days. The dried leaves were then ground to uniform texture using a mortar and pestle. The larger plant particles were removed and the finer powdered leaves were taken for the extraction. From that, one gram of each of the dried leaf sample was weighed separately and transferred to two different individual $50 \mathrm{~mL}$ beakers. $20 \mathrm{~mL}$ of Methanol was added to one beaker and 20 $\mathrm{mL}$ of acetone was added to another beaker, respectively. The Soxhlet apparatus was used for the extraction process. After the extraction, the extracts were filtered with the help of Whatman No. 1 (pore size $11 \mu \mathrm{M}$ ) filter paper to remove the larger debris. The filtrate was next centrifuged at $5000 \mathrm{rpm}$ for $15 \mathrm{~min}$ to remove the fine debris that was not removed by filtration. The clear supernatant was then taken and stored in glass vials and refrigerated at $4{ }^{\circ} \mathrm{C}$ for future study. This procedure was adopted for the preparation of dry extract for the other mangrove species.
Preparation of nutrient agar media and petri plates to study the inhibition zone. Nutrient agar media was prepared by dissolving $5.0 \mathrm{~g}$ peptone, $1.5 \mathrm{~g}$ yeast extract, $1.5 \mathrm{~g}$ beef extract, $5.0 \mathrm{~g} \mathrm{NaCl}$ and 20.0 g powdered agar in $1,000 \mathrm{~mL}$ of distilled water. The medium was sterilized in autoclave for $15 \mathrm{~min}$ at $15 \mathrm{psi}\left(\sim 121^{\circ} \mathrm{C}\right)$.

A volume of $15 \mathrm{~mL}$ nutrient agar media were then transferred to clean, sterilized Petri dishes with the help of sterilized pipettes. The number of petriplates was based on the number of samples. The plates were then allowed to gradually cool down and solidify. Upon solidification, the plates were inoculated with $0.1 \mathrm{~mL}$ of the fresh curd supernatant sample. The inocula were spread uniformly with the help of a sterilized spreader and were kept in an incubator at $37 \pm 1{ }^{\circ} \mathrm{C}$ for the bacterial culture to grow for $24 \mathrm{~h}$. The petri plates were placed in inverted manner to minimize aerial contamination.

On the next day, small cups were scooped using sterile needle/loop $(\sim 5 \mathrm{~mm}$ diameter). Then $0.1 \mathrm{~mL}$ of each of the dry and raw leaf extracts were poured into the cups (Well Diffusion Method). One cup with $0.1 \mathrm{~mL}$ sterile distilled water served as blank. The Petri plates were again incubated at $37 \pm 1{ }^{\circ} \mathrm{C}$. After $24 \mathrm{~h}$, the plates were observed for the zones of inhibition (Gulshan et al., 2005).

Preparation of nutrient broth and inoculation. Nutrient broth was prepared by prepared by following the recipe for the nutrient agar media bar the addition of agar. The nutrient broth was sterilized in an autoclave for $15 \mathrm{~min}$ at 15 psi pressure along with culture tubes and pipettes based on the total number of leaf extracts.

The nutrient broth, culture tubes and pipettes were allowed to cool down to room temperature. $15 \mathrm{~mL}$ of nutrient broth was transferred aseptically into respective culture tubes (marked according to the species, solvent and extraction source) using sterilized pipettes.

The leaf extracts were dried in room temperature through evaporation to negate the solvents and the remaining dried 
sediment was scrapped up completely and dissolved in sterilized distilled water to be used later and were stored in $-20^{\circ} \mathrm{C}$ refrigerator.

About $0.5 \mathrm{~mL}$ of fresh curd sample was inoculated to respective culture tubes containing $15 \mathrm{~mL}$ of nutrient broth. $1.0 \mathrm{~mL}$ of individual dry leaf extract and raw leaf extract (preserved active ingredient) of the subject species were added to respective culture tubes. A separate culture tube containing nutrient broth and inoculum served as control. Another culture tube with only nutrient broth served as blank. All the culture tubes were incubated at $37 \pm 1{ }^{\circ} \mathrm{C}$.

The bacterial cell density in each culture tube was measured with respect to the absorbance at a given wavelength (here
$600 \mathrm{~nm}$ ) with the help of a Systronics UV-VIS spectrophotometer depending on the colour of the broth and initial optical density (OD) values were recorded by taking aliquots of consistent volume from each tube and diluted uniformly to amplify the volume for the ease of measurement. After an interval of three days, the OD values of all the culture tubes with raw and dry leaf extract along with control were again noted down to detect the bacterial growth and the process continued till the bacterial growth declined, which in this case was after 7 days. The percentage suppression of the microbial growth by the mangrove leaf extracts was calculated using the formula:

$\%$ Suppression of growth $=$ [Optical Density of the cultures with leaf extracts/Optical Density of the Control without leaf extracts] $\times 100$

\section{Statistical analyses}

The data obtained and generated during the present study were interpreted with the help of ANOVA: Single Factor and F-tests: Two sample for variance studies. The analyses were performed with the help of Microsoft Excel 2007 software data analysis tool pack 2007.

\section{Results}

The study deals with the investigation on the potential antimicrobial activities of the mangrove plants of Sundarban mangrove ecosystems and the current account encompasses the results obtained from the studies on eight of the true mangrove species which is as follows.

From the Figures 3 and 4, it is quite evident that the suppressive effects of the antimicrobial agents extracted from the leaves of the eight mangrove species have exerted certain control over the milk spoilage microflora, irrespective of the extraction solvent since the final optical density of any of the cultures where leaf extracts were administered never quite reached the optical density recorded from the control culture, although some of the initial OD values were higher than te initial OD of the control. In comparison with methanol, leaf extracts obtained through the use of acetone suppressed the microbial growth to lesser extents as in more times than naught, the optical density values were higher in case of the culture spiked with the acetone extracted active substances. Apparently the antimicrobial activity of the leaf extracts were observed to be far more potential when procured from dry leaves than their fresher counterparts as the optical density hardly reached half the values it reached in case of raw leaf extracts. 


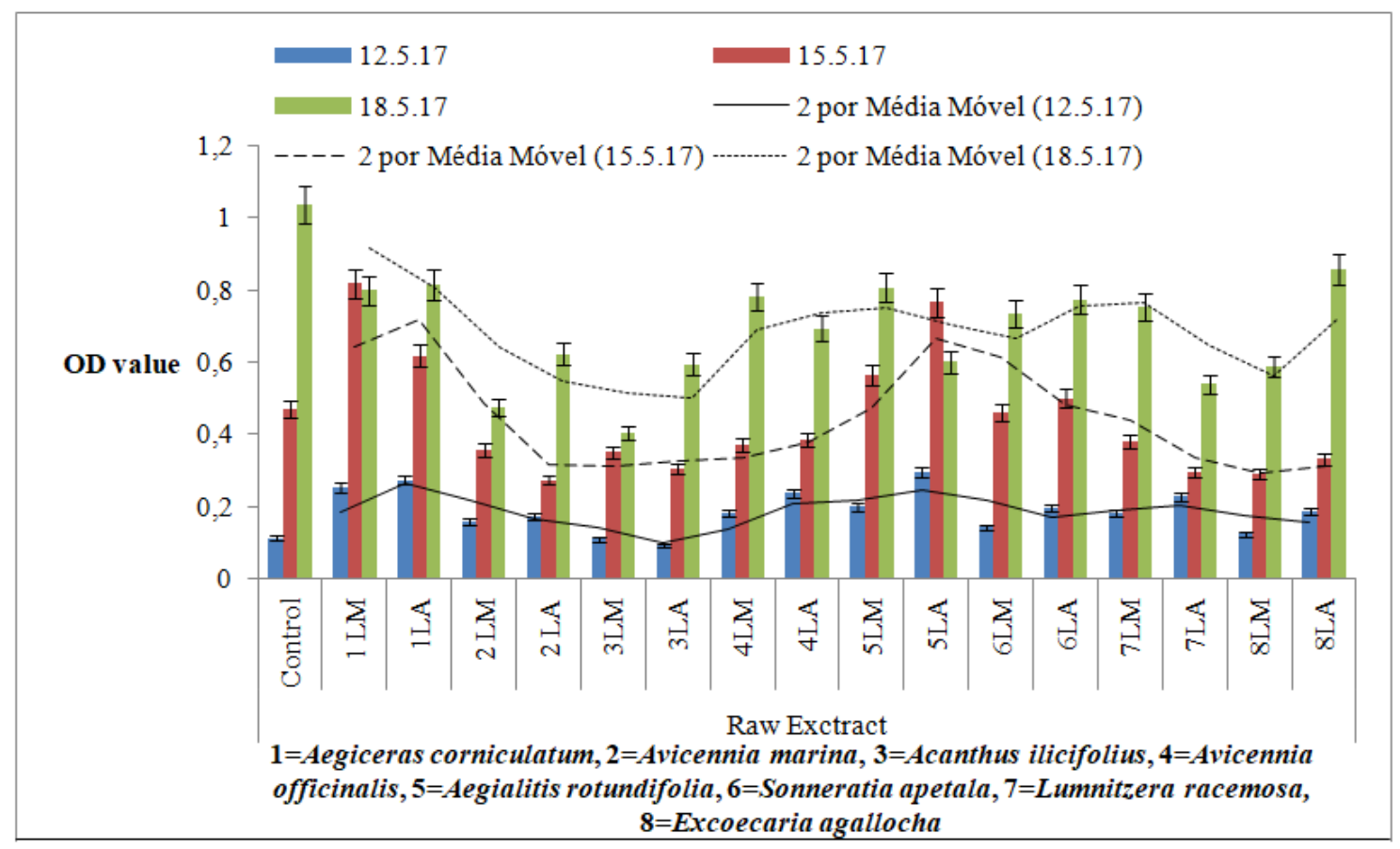

Figure 3. The comparison in between the raw leaf extracts from eight mangrove species using two solvents viz. methanol (M) and acetone (A) in the form of their growth inhibitory potential against milk spoilage microbes.

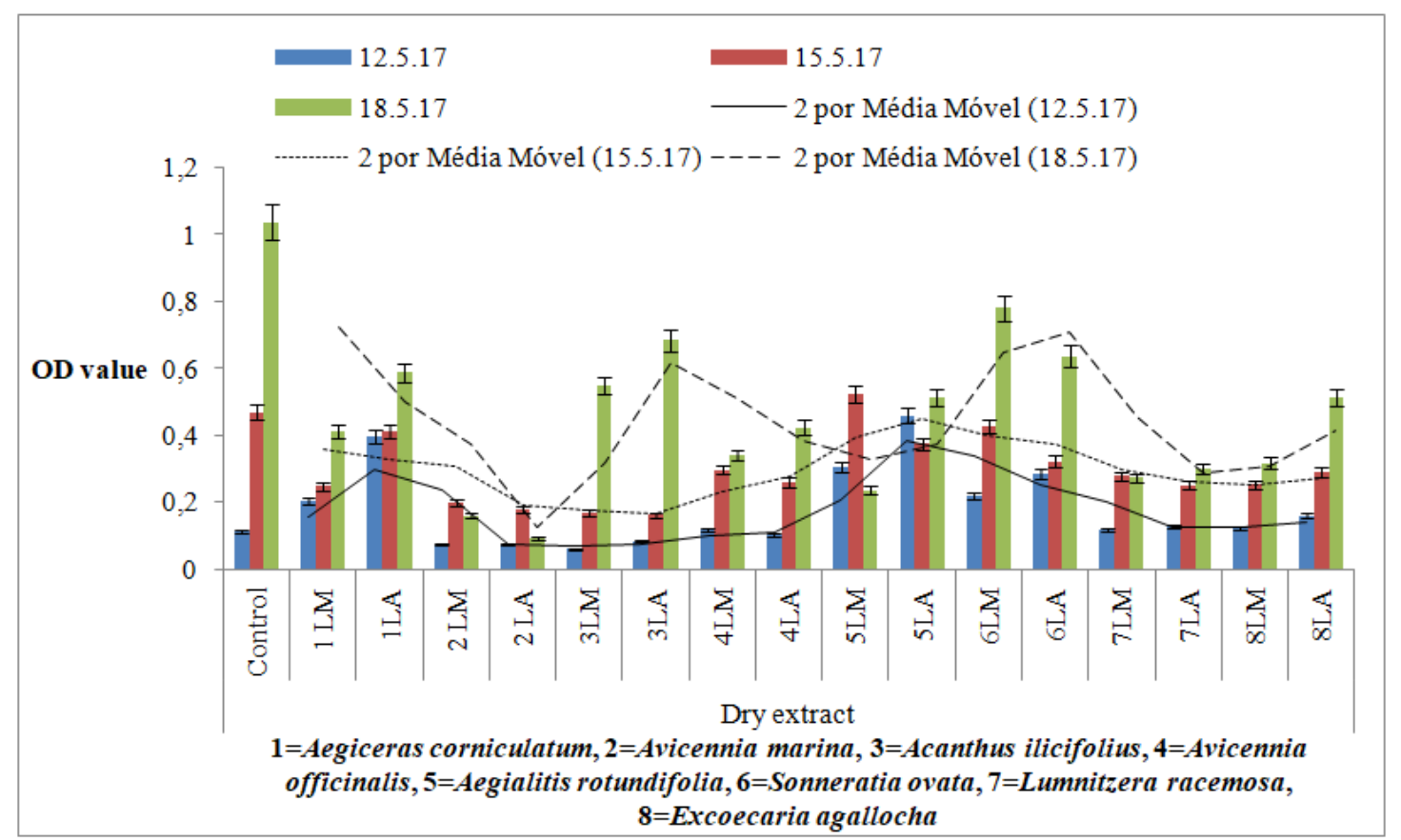

Figure 4. The comparison in between the dry leaf extracts from eight mangrove species using two solvents viz. methanol (M) and acetone (A) in the form of their growth inhibitory potential against milk spoilage microbes. 
The ANOVA single factor analyses recorded in Tables 1 and 2 pointed out that the values obtained during the study on the suppressive effects of the mangrove leaf extracts containing the antimicrobial agents, where the leaves were dried or used fresh, were of statistical significance and the null hypothesis was rejected, at 0.05 level of significance.

Table 1. ANOVA: Single factor summary for the raw leaf extracts from the selected eight mangrove plant species and their response as OD values compared with the untreated control. The groups represent the dates on which the data were procured. The $\alpha>>$ P-value and F > F critical value at $95 \%$ confidence level or 0.05 level of significance implies that the data sets in question were of statistical significance since the Null hypothesis was rejected.

\begin{tabular}{|c|c|c|c|c|c|c|}
\hline \multicolumn{7}{|l|}{ SUMMARY } \\
\hline Groups & Count & Sum & Average & Variance & & \\
\hline 12.05.17 & 16 & 2.852 & 0.17825 & 0.004708 & & \\
\hline 15.05.17 & 16 & 7.161 & 0.447563 & 0.027483 & & \\
\hline 18.05.17 & 16 & 10.834 & 0.677125 & 0.018055 & & \\
\hline \multicolumn{7}{|l|}{ ANOVA } \\
\hline Source of Variation & SS & $d f$ & $M S$ & $F$ & P-value & F crit \\
\hline Between Groups & 1.995224 & 2 & 0.997612 & 59.56455 & $2.27 \mathrm{E}-13$ & 3.204317 \\
\hline Within Groups & 0.753679 & 45 & 0.016748 & & & \\
\hline Total & 2.748902 & 47 & & & & \\
\hline$\alpha>>P @ \alpha=0.05$ & $\mathrm{~F}>\mathrm{F}$ crit & & & & & \\
\hline
\end{tabular}

Table 2. ANOVA: Single factor summary for the extracts from dried leaves of the selected eight mangrove plant species and their response as OD values compared with the untreated control. The groups represent the dates on which the data were procured. The $\alpha>>$ P-value and F $>\mathrm{F}$ critical value at $95 \%$ confidence level or 0.05 level of significance implies that the data sets in question were of statistical significance since the Null hypothesis was rejected.

\begin{tabular}{|c|c|c|c|c|c|c|}
\hline \multicolumn{7}{|l|}{ SUMMARY } \\
\hline Groups & Count & Sum & Average & Variance & & \\
\hline 12.05 .17 & 16 & 2.854 & 0.178375 & 0.015523 & & \\
\hline 15.05.17 & 16 & 6.006 & 0.375375 & 0.009856 & & \\
\hline 18.05.17 & 16 & 6.826 & 0.426625 & 0.037765 & & \\
\hline \multicolumn{7}{|l|}{ ANOVA } \\
\hline Source of Variation & $S S$ & $d f$ & MS & $F$ & P-value & F crit \\
\hline Between Groups & 0.549673 & 2 & 0.274836 & 13.05755 & 3.37E-05 & 3.204317 \\
\hline Within Groups & 0.947163 & 45 & 0.021048 & & & \\
\hline Total & 1.496836 & 47 & & & & \\
\hline$\alpha>>P @ \alpha=0.05$ & $\mathrm{~F}>\mathrm{F}$ crit & & & & & \\
\hline
\end{tabular}

A very interesting fact which has come to light is that in case of every species selected, whether the extracts were obtained from dry leaves or fresh, the ultimate optical densities of the nutrient broth mediated cultures, prior to the decline of the cultures, reached almost the same values thereby establishing unequivocally the presence suppressive efficiency of the mangrove leaf extracts against milk spoilage microbes and also implied that on the inhibitory effect of the leaf extracts may have worked in the same fashion in all the cultures whatever may the nature of inhibition be (to be worked upon in future).

The Figures 5 and 6 depict the percentage increase of the density of the cultures treated with the various leaf extract 
obtained from the selected mangrove plants using methanol and acetone in comparison to the increase in the same in cultures without any treatment i.e. the control to understand the effect of inhibition of the microbial growth by the mangrove leaf extracts. Any deviation in the pattern of the increase in optical density of the cultures compared with the control should suggest the nature and degree of resistance being offered by the mangrove leaf extracts on the milk spoilage microflora which were inoculated in the nutrient broths. It was noted that leaf extracts from Avicennia marina, Avicennia officinalis, Lumnitzera racemosa and Aegialitis rotundifolia among the species selected were able to exert relatively greater adverse impacts on the milk spoilage bacteria than others, although all the species exhibited some degree of suppressive effect. This preliminary observation was further vindicated by the calculation of the percentage of suppression of growth using the respective formula and is depicted in the Figures 7 and 8 which show that all the leaf extracts did offer resistance against the proliferation of the milk spoilage bacteria and by the 4th and 7th day from the initial inoculation the mean growth suppression eventuated by the raw leaf extracts were $104.1778 \pm 29.5371 \%$ and $65.2965 \pm 12.9573 \%$ and dry leaf extracts were $88.5318 \pm 23.4149 \%$ and $41.1403 \pm 18.7399 \%$ respectively with relatively greater suppression being observed in cultures treated with leaf extracts of Avicennia marina (values ranging between $42.1863 \pm 34.5842 \%$ and $66.6835 \pm 18.0872 \%)$ taking into account the seven day long incubation periods while all the others registered significant growth suppression values rendering them suitable candidates to study antimicrobial effects on milk spoilage microflora.

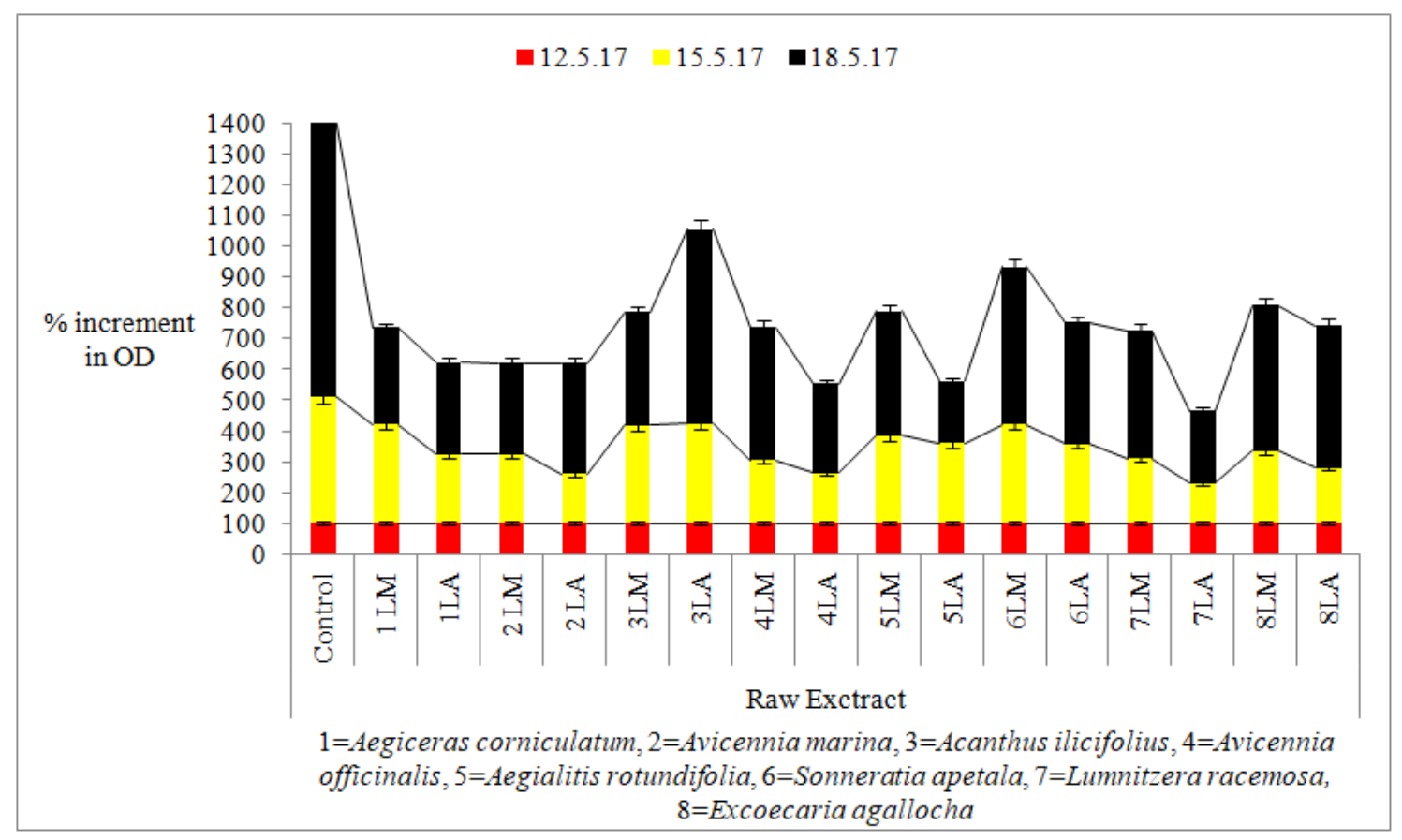

Figure 5. The comparison between raw leaf extracts from eight mangrove species using methanol (M) and acetone (A) on their suppressive efficacy against milk spoilage microbes expressed as percentage of increment in optical density of the cultures. 


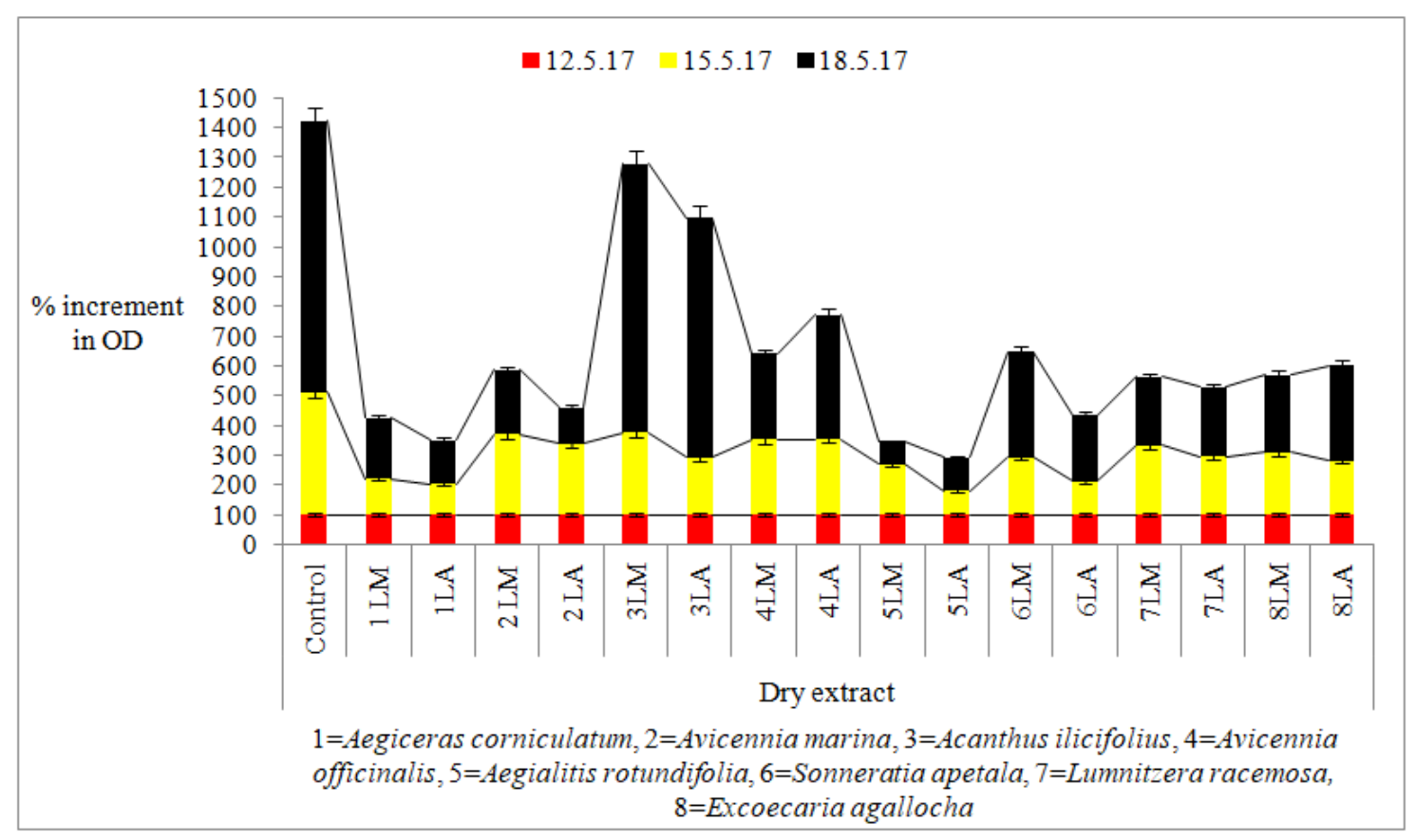

Figure 6. The comparison in between the dry leaf extracts from eight mangrove species using two solvents viz. methanol (M) and acetone (A) on their suppressive efficacy against milk spoilage microbes in terms of the percentage of change in optical density of the cultures.

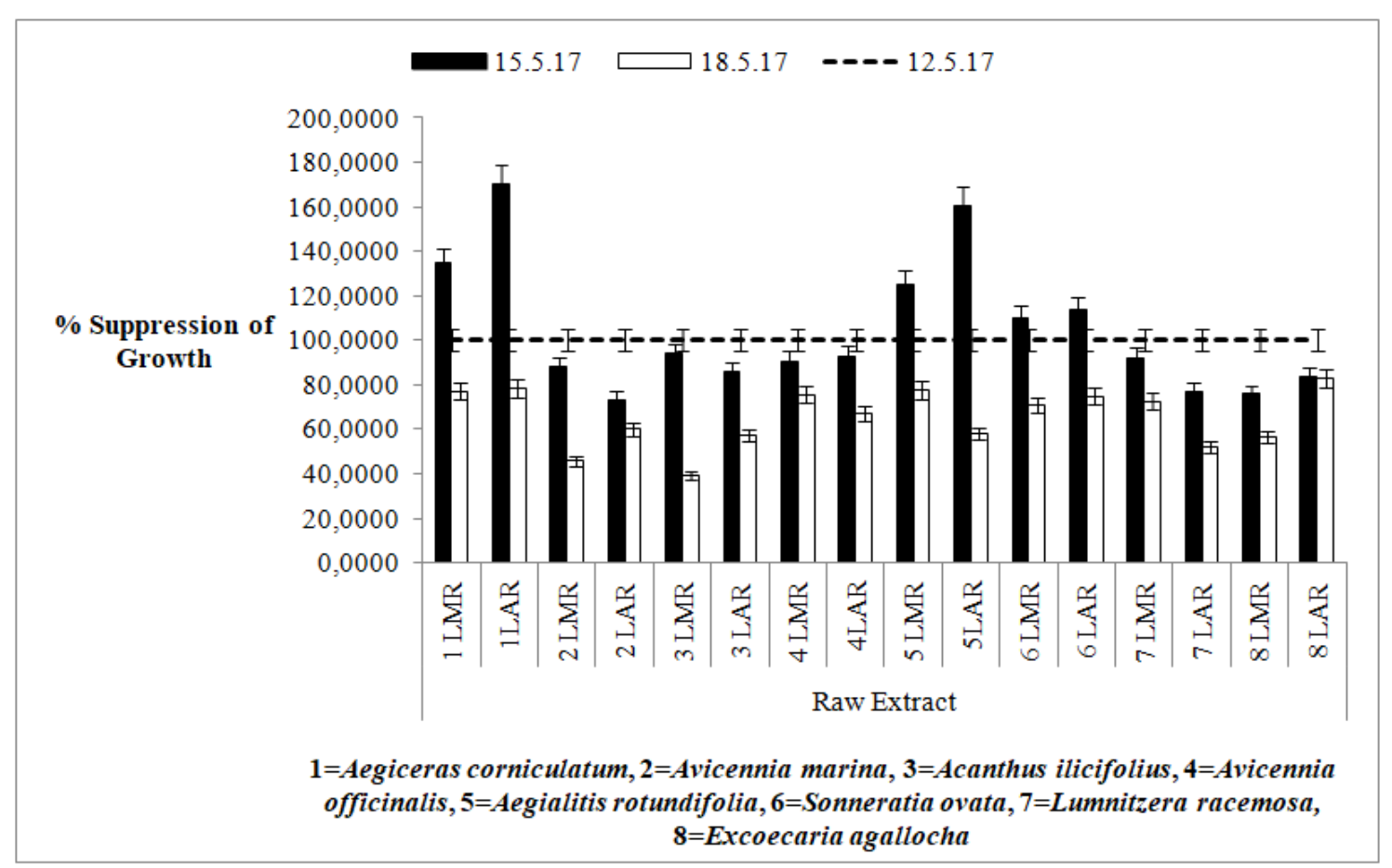

Figure 7. The percentage of suppression of growth by raw leaf extracts from eight mangrove species using two solvents viz. methanol (M) and acetone (A) against milk spoilage microbes obtained from curd supernatant. 


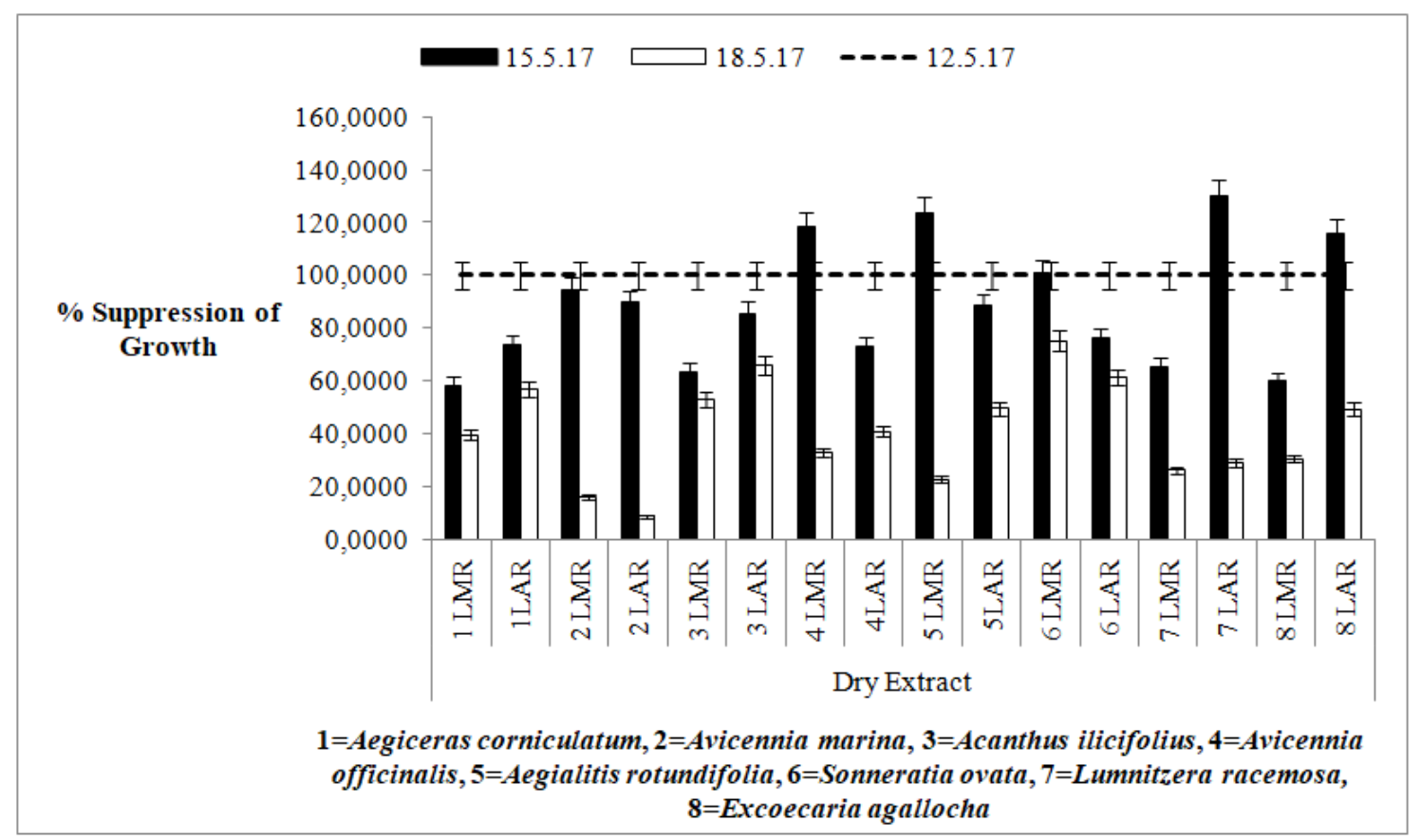

Figure 8. The percentage of suppression of growth by dry leaf extracts from eight mangrove species using two solvents viz. methanol (M) and acetone (A) against milk spoilage microbes from curd supernatants.

From the Figure 9 and 10 the inhibitory effect of the leaf extracts can be further observed in the form of inhibition zones on culture plates. Here also dry leaf extracts produced larger inhibition zones on petriplates with the mean inhibition zone diameter being $4.90 \pm 2.20 \mathrm{~mm}$ compared to $4.16 \pm 1.39 \mathrm{~mm}$ of the raw leaves at $10^{-6}$ and $6.06 \pm 2.55 \mathrm{~mm}$ in case of dry leaves compared to $5.34 \pm 1.37 \mathrm{~mm}$ observed with the raw leaves at the $10^{-9}$ dilution respectively and methanol and acetone extracts both resulted in more or less similar sized area being devoid of any microbial growth but acetone extracts however produced relatively larger inhibition zones. Among the two dilutions of the inocula, the $10^{-9}$ demonstrated largest inhibition zone diameters compared to $10^{-6}$ times diluted inocula.

Interestingly, all the selected species A. corniculatum, A. marina, A. ilicifolius, A. officinalis, A. rotundifolia, S. apetala, $L$. racemosa and E. agallocha demonstrated great efficiency in formation of growth inhibition zones on the Petri plates, irrespective of the solvents and in case of both fresh and dry leaves however, the extracts from A. rotundifolia, S. apetala and $L$. racemosa demonstrated comparatively greater antimicrobial potentials with $5.50 \pm 1.85 \mathrm{~mm} / 6.25 \pm 2.45$ $\mathrm{mm}, 5.75 \pm 1.19 \mathrm{~mm} / 6.00 \pm 1.98 \mathrm{~mm}, 4.50$ $\pm 0.90 \mathrm{~mm} / 6.25 \pm 2.15 \mathrm{~mm}$ and $5.50 \pm 1.87$ $\mathrm{mm} / 6.75 \pm 2.02 \mathrm{~mm}, 5.00 \pm 1.45 \mathrm{~mm} / 6.00$ $\pm 1.65 \mathrm{~mm}, 5.50 \pm 1.45 \mathrm{~mm} / 6.75 \pm 1.25$ $\mathrm{mm}$ of mean inhibition zone diameters by employing methanol and acetone extractions for both the raw/dry leaves, respectively. Extracts from dry leaves of Aegiceras corniculatum registered the highest values with $8.5 \mathrm{~mm}$ and $11 \mathrm{~mm}$ in $10^{-6}$ and $10^{-9}$ dilutions but values obtained from raw leaf extracts were much lower. 


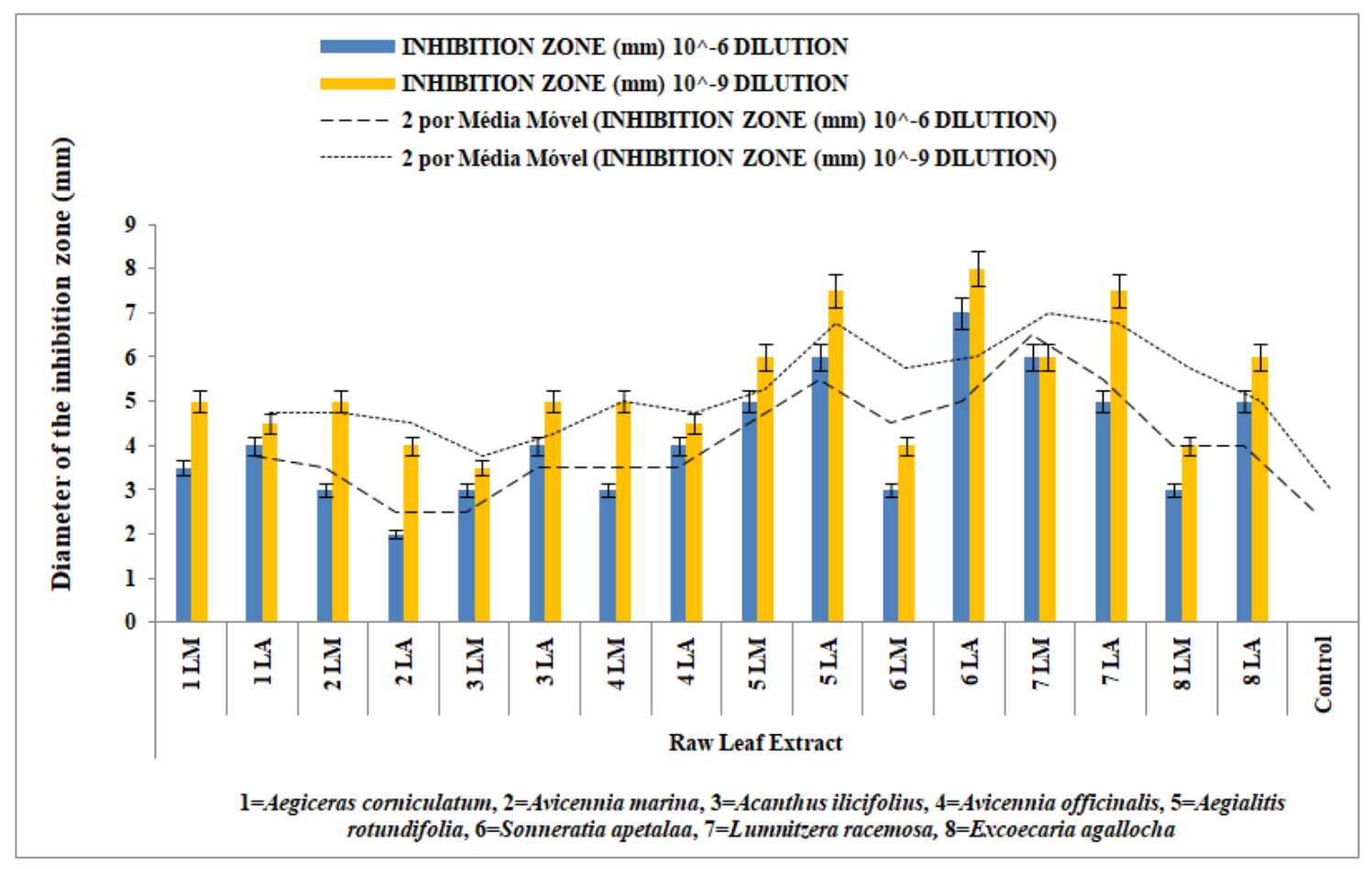

Figure 9. The comparison in between the inhibition zone diameter on milk spoilage microbial culture plates created by raw leaf extracts from eight mangrove species using two solvents viz. methanol and acetone.

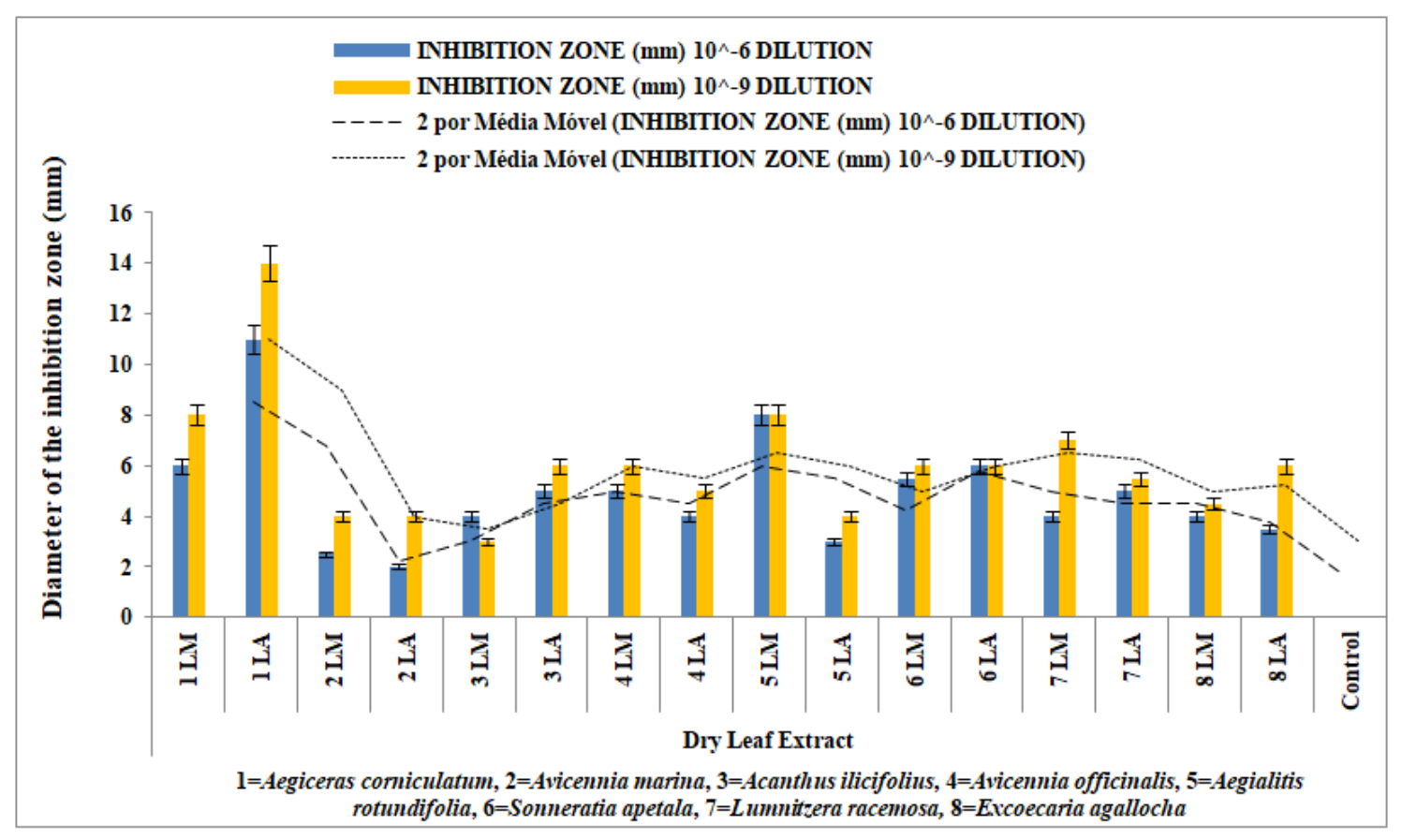

Figure 10. The comparison in between the inhibition zone diameter on milk spoilage microbial culture plates created by dry leaf extracts from eight mangrove species using two solvents viz. methanol and acetone. 
Two F-tests (Tables 3 and 4) were performed on the datasets generated from the inhibition zone experiments, by comparing the variations in the data obtained due of the different solvents used and also comparisons based on the dilution factors, yielded critical values that rendered the Null hypothesis to be rejected at 0.05 level of significance. Thus it is quite well evinced from all the information generated during the course of the study that the selected species of mangrove plants harbour substances within their leaves which to varying extents are very effective against milk spoilage bacteria, whether in low or higher concentrations.

Table 3. F-Test: Two-sample for variances performed on the data obtained on inhibition zones produced by methanol and acetone extracts from raw leaves of the selected mangrove species. The extract doses were administered to cultures of milk spoilage microbes at $10^{-6}$ and $10^{-9}$ dilutions.

\begin{tabular}{|c|c|c|}
\hline Raw Leaf Extracts & & \\
\hline \multicolumn{3}{|l|}{ F-Test Two-Sample for Variances } \\
\hline Dilution $\rightarrow$ & $10^{-6}$ times & $10^{-9}$ times \\
\hline Mean & 4.6176 & 5.7058 \\
\hline Variance & 5.9540 & 8.2830 \\
\hline Observations & 17 & 17 \\
\hline Df & 16 & 16 \\
\hline $\mathrm{F}$ & 0.7188 & \\
\hline $\mathrm{P}(\mathrm{F}<=\mathrm{f})$ one-tail & 0.2582 & \\
\hline F Critical one-tail & 0.4285 & \\
\hline \multicolumn{3}{|l|}{$\mathrm{F}>\mathrm{F}$ Critical one-tail, Null hypothesis is rejected } \\
\hline \multicolumn{3}{|l|}{ Dry Leaf Extracts } \\
\hline \multicolumn{3}{|l|}{ F-Test Two-Sample for Variances } \\
\hline Dilution $\rightarrow$ & $10^{-6}$ times & $10^{-9}$ times \\
\hline Mean & 3.9117 & 5.0294 \\
\hline Variance & 2.8198 & 3.4522 \\
\hline Observations & 17 & 17 \\
\hline $\mathrm{Df}$ & 16 & 16 \\
\hline $\mathrm{F}$ & 0.8168 & \\
\hline $\mathrm{P}(\mathrm{F}<=\mathrm{f})$ one-tail & 0.3452 & \\
\hline F Critical one-tail & 0.4285 & \\
\hline F>F Critical one-tail, Null hypothesis is rejected & & \\
\hline
\end{tabular}


Table 4. F-Test: Two-sample for variances performed on the data obtained on inhibition zones produced by methanol and acetone extracts from dried leaves of the selected mangrove species. The extract doses were administered to cultures of milk spoilage bacteria at similar dilutions (methanol and acetone extracts compared at $10^{-6}$ and $10^{-9}$ dilution levels respectively). The table highlights comparison of the data yielded from raw and dried leaf extract administrations at same dilutions $\left(10^{-6}\right.$ and $\left.10^{-9}\right)$ of the milk spoilage microbial culture.

\begin{tabular}{|l|l|l|}
\hline Raw and Dry Leaf Extracts & & \\
\hline F-Test Two-Sample for Variances & \multicolumn{1}{|c|}{} & \\
\hline \multicolumn{1}{|c|}{ Dilution $\rightarrow$} & $10^{-6}$ times & $10^{-6}$ times \\
\hline Mean & 4.9062 & 4.1562 \\
\hline Variance & 4.8406 & 1.9239 \\
\hline Observations & 16 & 16 \\
\hline Df & 15 & 15 \\
\hline F & 2.5160 & \\
\hline P(F<=f) one-tail & 0.0419 & \\
\hline F Critical one-tail & 2.4034 & \\
\hline F $>$ F Critical one-tail, Null hypothesis is rejected & & \\
\hline F-Test Two-Sample for Variances & & \\
\hline \multicolumn{1}{|c|}{ Dilution $\rightarrow$} & $10^{-9}$ times & $10^{-9}$ times \\
\hline Mean & 6.0625 & 5.3437 \\
\hline Variance & 6.5292 & 1.8906 \\
\hline Observations & 16 & 16 \\
\hline Df & 15 & 15 \\
\hline F & 3.4534 & \\
\hline P(F<=f) one-tail & 0.0109 & \\
\hline F Critical one-tail & 2.4034 & \\
\hline F $>$ F Critical one-tail, Null hypothesis is rejected & & \\
\hline
\end{tabular}

\section{Discussion}

Studies by Alizadeh-Behbahani et al. (2012) recorded anti fungal activities of Avicennia marina while there exists many other works focused on the anti-enteric bacterial potentials of this species, antimicrobial effects on plant and oral pathogens by bioactive substances derived from Avicennia alba were observed by Vadlapudi and Naidu (2009), inhibitory effects on Escherichia coli, Enterobacter aerogenes, Klebsiella pneumoniae, Pseudomonas aeruginosa, Bacillus subtilis, Lactobacillus delbrueckii, Staphylococcus aureus and Streptococcus pyrogenes of stem and root extracts from Avicennia officinalis were thoroughly studied by Sharief Md and Rao (2011), Saad et al. (2011, 2012) reported the presence of adverse effects of extracts from Lumnitzera littorea and Sonneratia alba on strains of Cryptococcus, Staphylococcus, Candida and Escherichia while Teja and
Ravishankar (2013) documented antimicrobial actions of ethanolic extracts derived from Sonneratia apetala against Pseudomonas, Proteus, Escherichia and Klebsiella. Laith and Najiah (2014) showed in their work the effectiveness of Excoecaria agallocha extracts against selected pathogenic bacteria were resistant to Nitrofurantion, Gentamycin and Neomycin etc; Powar and Gaikwad (2016) analysed the bioactive substance from bark extracts of Aegiceras corniculatum and revealed a host of compounds that are effective antimicrobials agents against a broad spectrum of microbes and antipathogenic activities of Aegialitis rotundifolia and Acanthus ilicifolius of Indian Sundarban were reported by Bakshi and Chaudhuri (2014) on Agrobacterium tumefaciens, Escherichia coli, Streptococcus mutans, Staphylococcus aureus, Aspergillus flavus etc.

The present study revealed the presence of antimicrobial effects against 
milk spoilage microflora in leaf extracts of eight true mangrove plant species as mentioned previously. There have been many studies, as mentioned above, intended to investigate the antibacterial, antiviral and antifungal efficacies of bioactive substances present in leaf, bark and root extracts of many mangrove species and many species are yet to be screened but literally no studies have ever been attempted to elicit the use of mangrove plant extracts in extending the shelf life of dairy products or any other prone to spoilage food items in the absence of means to sterilize them.

The antimicrobial activities of the mangrove leaf extracts on the milk spoilage microflora on the whole as observed in the Figures 3 to 10 in the form of optical density, growth suppression and growth inhibition zone measurements revealed the existence of certain degree of inhibitions on the growth and proliferation of the microbes present in the milk inocula. Avicennia marina, Avicennia officinalis, Lumnitzera racemosa and Aegialitis rotundifolia demonstrated greater inhibitory activities on the milk spoilage microbes than others in aqueous phase. Interestingly, species like Aegialitis rotundifolia, Sonneratia apetala, Lumnitzera racemosa and Excoecaria agallocha exhibited higher degrees of inhibition of growth as observed from the agar plate inhibition zones on the microbe cultures. This may be due to the fact that in liquid media the active substances yielded from these species exerted relatively weaker control on the bacterial growth than others but in drier media they produced greater adverse impact on the sustenance of the milk spoilage bacteria.

Although acetone is more polar in nature and thus a better organic solvent than methanol but the higher polarity might have brought about structural changes in the active agents rendering them, to some degree, less effective and hence methanolic extracts were observed to express better as microbial growth suppressants or deterrents.

A possible reason for dry leaf extracts to exert greater control in culture broths as detected through spectrophotometry may be the presence of considerable amount of moisture in the fresh leaves which makes it certain that the amount of leaf used for extraction was not so, an issue totally negated when using dried leaves. Hence fresher leaves that appeared $1 \mathrm{~g}$ in weight were in reality far less and the extraction from that amount would have quite expectedly yielded smaller quantities of active antimicrobial substances. But raw leaf extracts produced larger inhibition zones and methanol and acetone extracts both resulted in more or less similar sized area being devoid of any microbial growth. The extractions performed with the dry leaves yielded the absolute concentrations of the active substances present in the leaves which have the potential antimicrobial properties and accordingly the greater apparent affectivity of the dry leaves was observed to dominate over the raw leaf extracts as the latter produced relatively smaller inhibition zones. The antimicrobial substances in dry leaf extracts being presumably higher in concentration than the same volume of raw leaf extracts might have diffused better during the incubation period and hence resulted in the exertion of greater restrictive influence upon the growth and proliferation of the microbial communities. The percentage suppression of growth data presented in the Figures 7 and 8 more conclusively pointed out that dry leaf extracts affected the growth of the milk spoilage microbes in more adverse manner than the extracts obtained from raw leaves, irrespective of the solvent used, as observed from the data generated.

From Figures 9 and 10 it is evident that the diameter of the inhibition zones were larger on petriplates inoculated with $10^{-9}$ dilution of the inocula than $10^{-6}$ which is understandable since the same volume of leaf extracts should express greater suppressive influence on the culture containing $10^{-9}$ times diluted inocula than it would on inocula containing $10^{-6}$ dilutions of microbial concentrates and hence the colony formers would be comparatively greatly affected in the former than the latter and the bioactive antimicrobial substances in the leaf extracts would have possible 
diffused in larger area prior to the formations of colonies of spoilage microflora on the plates with higher degree of dilutions of the inocula.

Growth suppression in microbes might have come in many forms such as inhibiting cell wall synthesis, interruption of ribosomal subunits synthesis, cell cycle modification and/or halting it altogether, aberration in genetic materials, disruptions in transcriptional and translational processes etc and any one or a number of inhibitions may be affected by the active substances present in mangrove leaves. The fresh leaves that were subjected to the organic solvent mediated extraction process for the study yielded the active substances along with the water that was present within the leaves cytosol, thus rendering the extracts diluted to some degrees and upon evaporation of the solvents in room temperature (since both methanol and acetone are highly volatile and can easily evaporate in room temperature while water cannot, not at least in the same time span) the extracts still retained the moisture content which automatically made it comparatively less potent than the extracts obtained from the dried leaves which had no innate moisture to interfere with the efficiency of the compounds against microbes.

The data provided in the Tables 1 to 4 represent the statistical analysis performed on the data obtained during the study using ANOVA and F-tests, both of which resulted in the rejection of the null hypothesis since the $\alpha$ values at 0.05 level of significance was always greater than the probability $(\mathrm{P})$ values and the $\mathrm{F}$ values were always greater than the critical values thus signifying the existence of significance in the variances of the means of the data sets considered.

\section{Conclusion}

Mangrove species viz. Aegiceras corniculatum, Avicennia marina, Avicennia officinalis, Acanthus ilicifolius, Aegialitis rotundifolia, Sonneratia apetala, Lumnitzera racemosa and Excoecaria agallocha were observed to be effective against milk spoilage microbe samples obtained from curd supernatants. The mature leaf extracts of the aforementioned mangrove species seem to exert growth suppressive effects on the microbes. The antimicrobial activities of extracts from dried leaves were far more potential compared to the fresh leaf extracts. In comparison to methanol, leaf extracts through the use of acetone suppressed the microbial growth to lesser extents. Although acetone is more polar and better organic solvent than methanol but this higher dissolubility might have brought about structural changes in the active agents rendering them, to some degree, less effective.

In case of all the eight species selected, whether the extracts were obtained from dry leaves or fresh and methanol or acetone, the density of microflora, in the broth, prior to the decline reached nearly similar values, suggesting more or less similar milk spoilage microfloral growth suppressive efficacy of the mangrove leaf extracts. Leaf extracts of species viz. Avicennia marina, Avicennia officinalis, Lumnitzera racemosa and Aegialitis rotundifolia were able to exert relatively greater adverse impacts on the milk spoilage bacteria than others, although all the species exhibited some degree of suppressive effect. Interestingly, species like Aegialitis rotundifolia, Sonneratia apetala, Lumnitzera racemosa and Excoecaria agallocha demonstrated greater potentiality in formation of larger growth inhibition zones on the petri plates in relatively drier conditions, both in case of raw and dry leaf extracts and with both the solvents.

This is the very first time the selected species have been dealt with in respect to their anti-milk spoilage microflora activities and that too from halophytes of Bakkhali and Frasergunj fringe mangroves. It is just the initiation and more fascinating findings await those that aspire to study on this aspect in future and only through more rigorous studies shall we be able to extract more insights on the beneficial roles of mangroves and to do so we must try to protect the mangrove 
ecosystem in all its intricate complexities so that we continue to reap benefits from them in the years to come as there are none in their absence.

\section{Acknowledgement}

The authors wish to express their gratitude to the department of marine science of the University of Calcutta for the materialistic and infrastructural supports provided during the period of the study. The expenditure was borne partially by the authors and partially from contingencies of a Central Scientific and Industrial Research (CSIR), New Delhi, India major scientific project (Scheme No: 24(0330)/14/EMR-II) for which the contribution from CSIR is gratefully acknowledged.

\section{Conflict of interests}

The authors declare that there are no conflicts of interest.

\section{References}

Abeysinghe, P. D.; Vithanawasam, M.; Pathirana, R. N.; Abeysinghe, S. Preliminary in vitro screening of some mangrove plant extracts for antibacterial compounds against clinical bacterial isolates from different sources. 1st Science Symposium Proceeding, v. 1, p. 22-25, 2000.

Agoramoorthy, G.; Chandrasekaran, M.; Venkatesalu, V.; Hsu, M. J. Antibacterial and antifungal activities of fatty acid methyl esters of the blind-your eye mangrove from India. Brazilian Journal of Microbiology, v. 38, p. 739-742, 2007. http://doi.org/10.1590/S151783822007000400028

Aliero, A.; Aliero, B. L.; Buhari, U. Preliminary phytochemical and antibacterial screening of Scadoxus multiflorus. International Journal of Pure and Applied Science, v. 2, p. 13-17, 2008.

Alizadeh-Behbahani, B.; Tabatabaei-Yazdi, F.; Shahidi, F.; Mohebbi, M. Antimicrobial activity of Avicennia marina extracts ethanol, methanol \& glycerin against Penicillium digitatum (citrus green mold). Scientific Journal of Microbiology, v. 1, No. 7, p. 147-151, 2012. Available from: <http://sjournals.com/
index.php/SJMi/article/view/406/pdf_1>. Accessed on: May 25, 2017.

Bandaranayake, W. M. Bioactivities, bioactive compounds and chemical constituents of mangrove plants. Wetlands Ecology and Management, v. 10, no. 6, p. 421-452, 2002. https://doi.org/10.1023/A:1021397624349

Bandaranayake, W. M. Economic, traditional and medicinal uses of mangroves. Townsville: Australian Institute of Marine Science, 1999. (AIMS Report, No. 28).

Bandaranayake, W. M. Survey of mangrove plants from Northern Australia for phytochemical constituents and UV-absorbing compounds. Current Topics in Phytochemistry, v. 14, p. 60-72, 1995.

Bhimba, B. V.; Meenupriya, J.; Joel, E. L.; Naveena, D. E.; Kumar, S.; Thangaraj, M. Antibacterial activity and characterization of secondary metabolites isolated from mangrove plant Avicennia officinalis. Asian Pacific Journal of Tropical Medicine, v. 3, p. 544546, 2010. https://doi.org/10.1016/S19957645(10)60131-9

Biswas, H.; Dey, M.; Ganguly, D.; De, T. K.; Ghosh, S.; Jana, T. K. Comparative analysis of phytoplankton composition and abundance over a two-decade period at the land-ocean boundary of a tropical mangrove ecosystem. Estuaries and Coasts, v. 33, No. 2, p. 384-394, 2010. https://doi.org/10.1007/s12237-009-9193-5

Chandrasekaran, M.; Kannathasan, K.; Venkatesalu, V.; Prabhakar, K. Antibacterial activity of some salt marsh halophytes and mangrove plants against methicillin resistant Staphylococcus aureus. World Journal of Microbiology and Biotechnology, v. 2, p. 155160, 2009. https://doi.org/10.1007/s11274-0089869-1

Gazim, Z. C.; Rezende, C. M.; Fraga, S. R.; Svidzinski, T. I.; Cortez, D. A. Antibacterial activity of the essential oil from Calendula officinalis L. (Asteraceae) growing in Brazil. Brazilian Journal of Microbiology, v. 39, p. 61-63, 2008. http://dx.doi.org/10.1590/ S1517-83822008000100015

Gulshan, N.; Radhakrishnan, M.; Balagurunathan, R. Antimicrobial compounds from certain Indian medicinal plants against multi drug resistant bacteria. Indian Jounal of Applied Microbiology, v. 1, no. 1, p. 23-28, 2005.

Jacquelyn, G. B. Microbiology principles and exploration. 5. ed. New York: John Wiley and Sons, 2002. 
Kokpol, U.; Chittawong, V.; Mills, H. D. Chemical constituents of the roots of Acanthus ilicifolius. Journal of Natural Products, v. 49, no. 2, p. 355-356, 1984. https://doi.org/10.1021/ np50044a033

Laith, A. A.; Najiah, M. Antimicrobial activities of blinding tree, Excoecaria agallocha against selected bacterial pathogens. Journal of Microbiology and Antimicrobials, v. 6, no. 2, p. 29-36, 2014. https://doi.org/10.5897/ JMA2013.0291

Littleton, J.; Rogers, T.; Falcone, D. Novel approaches to plant drug discovery based on high throughput pharmacological screening and genetic manipulation. Life Sciences, v. 78, no. 5, p. 467-475, 2005. https://doi.org/10.1016/ j.lfs.2005.09.013

Mojab, F.; Poursaeed, M.; Mehrgan, H.; Pakdaman, S. Antibacterial activity of Thymus daenensis methanol extract. Pakistan Journal of Pharmacology Science, v. 21, p. 210-213, 2008.

Morales, G.; Paredes, A.; Sierra, P.; Loyola, L. A. Antimicrobial activity of three baccharis species used in the traditional medicine of Northern Chile. Molecules, v. 13, p. 790-794, 2008. http://dx.doi.org/10.3390/molecules130 40790

Mukherjee, A.; Das, S.; Chakraborty, S.; De, T. $\mathrm{K}$. An ex situ and in vitro approach to delineate pennate diatom species with bioindicator potentials in a well mixed tropical estuarine ecosystem. Brazilian Journal of Biological Sciences, v. 3, no. 6, p. 299-317, 2016. https://doi.org/10.21472/bjbs.030607

Mukhopadhyay, S. K.; Biswas, H.; De, T. K.; Jana, T. K. Fluxes of nutrients from the tropical River Hoogly at the land-ocean boundary of Sundarban, NE coast of Bay of Bengal. Journal of Marine Systems, v. 62, p. 9-21, 2006. https://doi.org/10.1016/j.jmarsys.2006.03.004

Nascimento, G. G. F.; Locatelli, J.; Freitas, P. C.; Silva, G. L. Antibacterial activity of plant extracts and phytochemicals on antibiotic resistant bacteria. Brazilian Journal of Microbiology, v. 31, p. 247-256, 2000. https://doi.org/10.1590/S1517-838220000004 00003

Nebedum, J.; Ajeigbe, K.; Nwobodo, E.; Uba, C.; Adesanya, O.; Fadare, O.; Ofusori, D. Comparative study of the ethanolic extracts of four Nigerian plants against some pathogenic microorganisms. Res. J. Med. Plant, v. 3, p. 23-28, 2009. http://dx.doi.org/10.3923/ rjmp.2009.23.28
Opra, E. U.; Wokocha, R. C. Efficacy of some plant extracts on the in vitro and in vivo control of Xanthomonas campestris pv. vesicatoria. Agricultural Journal, v. 3, p. 163-170, 2008.

Panda, S. K.; Thatoi, H. N.; Dutta, S. K. Antibacterial activity and phytochemical screening of leaf and bark extracts of Vitex negundo I. from Similipal Biosphere Reserve, Orissa. Journal of Medicinal Plants Research, v. 3, p. 294-300, 2009. Available from: $<$ http://www.academicjournals.org/article/articl e1380377015_Panda et al.pdf $>$. Accessed on: May 23, 2017.

Powar, P.; Gaikwad, D. GC-MS Analysis of bioactive compounds of Aegiceras corniculatum bark. Indian Journal of Plant Sciences, v. 5, no. 3, p. 13-17, 2016. Available from: $<$ http://www.cibtech.org/J-Plant-

Sciences/PUBLICATIONS/2016-VOL/JPSVOL-5-NO-3/03-JPS-003-PRATISHTHAANALYSIS.pdf> . Accessed on: May 23, 2017. Rajkrishnan, A.; Ponnusamy, K. Antifungal activity of Clerodendrum inerme (L.) and Clerodendrum phlomidis (L.). Turkian Journal of Biology, v. 30, p. 139-142, 2006. Available from: <http://journals.tubitak.gov.tr/biology/ issues/biy-06-30-3/biy-30-3-4-0510-4.pdf > .

Accessed on: May 23, 2017.

Saad, S.; Taher, M.; Susanti, D.; Qaralleh, H.; Izyani, A. F. Awang, Bt. In vitro antimicrobial activity of mangrove plant Sonneratia alba. Asian Pacific Journal of Tropical Biomedicine, v. 2, no. 6, p. 427-429, 2012. https://dx.doi.org/10.1016/S2221-1691(12) 60069-0

Saad, S.; Taher, M.; Susanti, D.; Qaralleh, H.; Izyani, A. F.; Awang, Bt. Antimicrobial activity of mangrove plant (Lumnitzera littorea). Asian Pacific Journal of Tropical Biomedicine, v. 4, no. 7, p. 523-525, 2011. https://doi.org/10.1016/ S1995-7645(11)60138-7

Saravanan, D.; Radhakrishnan, M. Antimicrobial activity of mangrove leaves against drug resistant pathogens. International Journal of Pharm Tech Research, v. 9, no. 1, p. 141-146, 2016. Available from: <http://sphinxsai.com/2016/ph_vol9_no1/1/(141 -146)V9N1PT.pdf $>$. Accessed on: May 23, 2017.

Sayyed, H.; Yogita, P.; Javesh, P.; Lakshmikant, B.; Sunil, P.; Goldee, S. P. Antibacterial and antifungal potential of Clerodendrum inerme crude extracts against some human pathogenic microorganism. Pharmacology Online, v. 2, p. 75-79, 2008. 
Sharief, Md. N.; Rao, U. V. Antibacterial activity of stem and root extracts of Avicennia Officinalis L. International Journal of Pharmaceutical Applications, v. 2, no. 4, p. 231-236, 2011. Available from: $<$ https://bipublication.com/files/IJPAv2i4201104.pdf $>$. Accessed on: May 23, 2017.

Teja, V. P.; Ravishankar, K. Preliminary phytochemical investigation and in vitro antimicrobial activity of ethanolic extracts of Sonneratia apetala plant. International Research Journal of Pharmacy, v. 4, no. 6, p. 84-87, 2013. https://doi.org/10.7897/22308407.04619

Vadlapudi, V.; Naidu, K. C. Bioactivity of marine mangrove plant Avicennia alba on selected plant and oral pathogens. International Journal of ChemTech Research, v. 1, no. 4, p. 1213-1216, 2009. Available from: $<$ http://sphinxsai.com/CTVOL4/ct_pdf_vol_4/C $\mathrm{T}=69$ (1313-1316).pdf $>$. Accessed on: May 23, 2017.

License information: This is an open-access article distributed under the terms of the Creative Commons Attribution License, which permits unrestricted use, distribution, and reproduction in any medium, provided the original work is properly cited.

Braz. J. Biol. Sci., 2017, v. 4, No. 8, p. 273-292. 